\section{O PRÓLOGO DE GEÓRGICAS III E OS DEMAIS PRÓLOGOS DO POEMA: UMA ABORDAGEM DESCRITIVO-COMPARATIVA}

\author{
Matheus Trevizam* \\ Recebido em: 07/01/2019 \\ Aprovado em: 25/07/2019
}

\begin{abstract}
RESUMO: Neste artigo, intentamos tratar do prólogo do livro III das Geórgicas de Virgílio, em que se abordam assuntos em relação com a pecuária. De início, após a delimitação da importância do tema proemial na literatura antiga, apresentamos alguns traços específicos deste terceiro prólogo. Esses traços - que depois seriam "retomados" na abertura de Eneida I - correspondem à sumarização dos assuntos a serem tratados por Virgílio, à metalinguagem, à invocação divina, ao estabelecimento de elos entre patrono e poeta e a algum realce dos tópicos abordados na mesma parte da obra didática virgiliana. Enfim, comparamos sucintamente o prólogo de Geórgicas III com os demais do poema, disso resultando que ele se aproxime, pela extensão e complexidade, daquele do livro I, mas se afaste, em pontos parecidos, dos relativos aos livros II e IV.
\end{abstract}

PALAVRAS-CHAVE: Prólogo; Geórgicas; comparação; estrutura.

\section{THE PROLOGUE OF GEORGICS III AND THE OTHER PROLOGUES OF THE POEM: A DESCRIPTIVE AND COMPARATIVE APPROACH}

* Professor Associado III de língua e literatura latina, Universidade Federal de Minas Gerais. mattrevi2017@gmail.com 
the prologue to Georgics III to other prologues of the poem, obtaining as a result that it can be equated, due to its extension and complexity, with the one of the first book, while it differs, in similar points, from the prologues associated with books II and IV.

KEYWORDS: Prologue; Georgics; comparison; structure.

\section{INTRODUÇÃo DA QUESTÃo E DE SUA IMPORTÂNCIA NA LITERATURA ANTIGA}

A prática dos antigos oradores e poetas revela, de sua parte, especial cautela com a composição dos segmentos introdutórios de discursos ou obras. No tocante à preceituação retórica, em princípio voltada a oferecer diretrizes para a feitura de textos prosísticos a serem apresentados diante de um público de juízes (gênero judiciário), pares em assembleia (gênero deliberativo) ou ouvintes de elogios ou detrações (gênero epidítico ou demonstrativo), a problemática da estrutura do exordium ("exórdio", "prólogo") recebeu desenvolvimentos que, em última instância, destinam-se a favorecer a persuasão dos ouvintes desde as linhas iniciais dos discursos (Pernot, 2000, p. 288).

$\mathrm{Na}$ Rhetorica ad Herennium, tratado oriundo do primeiro século a.C., dividiu-se o exordium em duas tipologias, atinentes ao "proêmio" (prohemium ou principium) e à "insinuação" (insinuatio); corresponde à primeira introduzir os discursos com vistas a tornar, de imediato, os espíritos do público dispostos a ouvir: dessa forma, benévolo, dócil e atento ele se faz. ${ }^{1}$ Por outro lado, é preciso começar pela insinuatio quando o ganho da adesão dos ouvintes não é tão garantido, seja porque a causa defendida lhes gera o repúdio, seja porque se considera terem eles, já, sido persuadidos pela fala do adversário, seja porque se cansaram da escuta da exposição precedente (Janson, 1964, p. 25). Diante de tais circunstâncias menos propícias ao ofício oratório, portanto, a insinuatio ocorre pela via da tentativa de minimizar inconvenientes, o que se dá, por exemplo, negando o cometimento do ato abominável imputado a alguém por seu adversário, iniciando o que se for dizer de preferência pela última frase tomada a ele ou incitando o público ao riso, sempre instigador do desejo de ouvir mais (Cícero, $A d$ C. Herennium, I, VI, 9 et seq.).

Por sua vez, o próprio fazer dos poetas antigos nos mostra que atribuíram aos inícios das obras importantes funções típicas, como a apresentação resumida dos assuntos,

\footnotetext{
${ }^{1}$ Veja-se descrição de Janson (1964, p. 25) a partir da Rhetorica ad Herennium: "The content of the section on exordium was briefly as follows. An introduction might be either a prooemium or an insinuatio. The purpose of a prooemium was to make the listener beneuolum, docile, attentum". A parte correspondente da própria Rhetorica encontra-se entre as rubricas da inuentio, em I, IV, 6 et seq.
} 
a metalinguagem, ${ }^{2}$ a menção patronal, ${ }^{3}$ a invocação divina e, de algum modo, a boa "recomendação" dos temas a serem desenvolvidos do começo ao fim de certos textos. Então, optando por apresentar como se cumprem essas funções, primeiro, no canto I da Eneida do mesmo Virgílio, intentamos, sobretudo, demonstrar que seu emprego, no prólogo de Geórgicas III, não correspondeu a algo fortuito, no sentido de apenas encontrável uma única vez na obra do poeta em jogo, mas sim a um modo compositivo recorrentemente pensado com o objetivo de favorecer a eficaz introdução do leitor a poemas inteiros, ou a importantes passagens textuais. Ora, como sabemos, a escrita da Eneida, obra de certa forma "maior" de Virgílio, ${ }^{4}$ seguiu-se àquela das Geórgicas na medida em que, tendo "publicado" esse último poema em 29 a.C., o autor logo se pôs a compor sua obra épica por um período estendido dez anos à frente, até 19 a.C.

Ademais, não são gratuitos os elos que se podem estabelecer entre, especificamente, a Eneida e o livro III do poema didático virgiliano: esse último se inicia, como adiante demonstraremos por meio de mais detalhes, com um prólogo imbuído de teores guerreiros,

${ }^{2}$ Os inícios de quaisquer obras - e de suas partes - sempre constituíram, na Antiguidade, importantes pontos para a discussão, mesmo que sutil, de questões envolvidas em sua feitura; veja-se Sharrock sobre o que lhe parece ser a natureza altamente metapoética do episódio de Dédalo e Ícaro, tal como narrado em princípios da Ars amatoria ovidiana - v. 21 et seq. (1994, p. 90: "In addition to its position in an important literary tradition, the passage is also foregrounded by its position as a hinge in this poem. As the second proem of the Ars it is tailor-made for reflection of and reflection on the poetry of Ovidian verse. It is at the beginning of this book, the middle book of the whole work"). Em começos da Eneida, um elementar funcionamento metaliguístico já se delineia pelo emprego do verbo cano ("canto") de I, 1, pois, assim, Virgílio "noticia" ao público que inicia um cântico - não outra modalidade discursiva qualquer -, contextualmente celebrante dos feitos de Eneias. Dessa forma, retira da banalidade suas presentes palavras e seu assunto no poema e insere-se na mesma tradição da épica homérica (Homero, Odisseia I, 1-2: "O homem multiversátil, Musa, canta, as muitas/ errâncias, destruída Troia, pólis sacra...” - trad. Trajano Vieira, grifo nosso).

${ }^{3}$ Trata-se, aqui, de mencionar o instigador da feitura da obra, ou mesmo, em sobreposição funcional (e até de identidade), o dedicatário de um dado texto. Fontes (2000, p. 41-42): "Seus cantos em louvor às armas e barões assinalados Camões os oferece à 'bem nascida segurança/ da lusitana antiga liberdade', ao 'tenro e novo ramo florescente/ de hua arvore de Christo mais amada/ que nenhuma nascida no Ocidente', isto é, ao 'poderoso Rei, cujo alto Imperio/ o sol logo em nascendo vê primeiro', inscrevendo-se, assim, no campo de uma prática textual já conhecida dos antigos romanos, que talvez a tenham inaugurado; basta recordar, entre muitos exemplos famosos, Virgílio a invocar, na abertura das Geórgicas, o nome de Mecenas, Quid faciat laestas segetes, quo sidere terram/ uertere, Maecenas (...)/ bic canere incipiam".

${ }^{4}$ Independentemente do fato de alguns críticos/leitores procederem ao destaque das Geórgicas sob o ponto de vista do apuro formal e da versificação (Dalzell, 1996, p. 105), é notório que a Eneida, modelo inconteste da épica posterior no Ocidente, impõe-se já pela escolha do gênero prevalente (épico-heroico, não didático), pelos profundos significados históricos de que se impregnou no alvorecer da Pax Augustana e por sua mais ampla adoção como parâmetro compositivo para autores do porte de Dante Alighieri (Divina Comédia, 1304-1321), Luís Vaz de Camões (Os Lusíadas, 1580) e Torquato Tasso (Jerusalém Libertada, 1581). 
celebratórios da "divindade" de Augusto e, na verdade, "anunciador" de uma empresa épica futura (Thomas, em seu comentário a Virgil, 1994b, p. 36). Justamente, trata-se nos dois primeiros casos de direcionamentos de sentido de todo associáveis à Eneida, que inclusive encontrou na atribuição de ascendência sagrada à gens Iulia ${ }^{5}$ - através de Iulo, filho de Eneias e neto de Vênus - um modo de enaltecer a Dinastia nascente.

Ainda sob o aspecto das similaridades temáticas a unirem tal epopeia e, em particular, o livro III das Geórgicas, acrescentamos ao menos que a inclusão e o relevo da abordagem dos mais "nobres" equinos nessa parte do poema didático citado - sendo que, com fins de tração ou carga, nos fundi rustici romanos, deveria prevalecer a recorrência a bovinos e/ou meros burros (Robert, 1985, p. 269) - contribuem para dotar a terceira subdivisão geórgica de colorações, notadamente, épicas, como dissemos em outro contexto. Em Geórgicas III, 83-85, Virgílio enfatizara que o tipo ideal de equino de certo modo "anseia” por atirar-se a uma zona de conflito bélico, podendo-se notá-lo pelas próprias reações físicas - tremor das orelhas e membros, resfolegar contínuo etc. - de um espécime idôneo (Trevizam, 2018, p. 81).

Derradeiramente, assim como se tem notado desde Sérvio Honorato, a bipartição estrutural da Eneida entre duas metades, ${ }^{6}$ não faltando sequer um segundo "prólogo" em canto VII, 37-45 (Vasconcellos, 2001, p. 201), o livro III das Geórgicas, depois de seu prólogo inicial, apresenta outro (v. 284-294) em que o poeta, conforme explicaremos, sinaliza o direcionamento temático para a abordagem dos animais de pequeno porte (caprinos e ovinos - v. 295-473), após desenvolver assuntos técnicos vinculados às manadas de bois e aos cavalos (v. 49-283). Eis abaixo, seguidamente a essa breve justificativa metodológica, o trecho introdutório da Eneida, que nos interessa comentar:

Arma uirumque cano, Troiae qui primus ab oris

Italiam fato profugus Lauiniaque uenit

litora, multum ille et terris iactatus et alto

ui superum saeuae memorem Iunonis ob iram, multa quoque et bello passus, dum conderet urbem

inferretque deos Latio, genus unde Latinum

Albanique patres atque altae moenia Romae.

Musa, mihi causas memora, quo numine laeso

quidue dolens regina deum tot uoluere casus

\footnotetext{
${ }^{5}$ A mesma de Caio Júlio César e, por extensão, de Augusto, seu filho adotivo.

${ }^{6}$ Maurus Seruius Honoratus, In Vergilii Aeneidos Librum Septimum, v. 1: Vt et in principio diximus, in duas partes hoc opus dinisum est: nam primi sex ad imaginem Odyssiae dicti sunt, quos personarum et adlocutionum uarietate constat esse grauiores, hi autem sex qui sequnntur ad imaginem Iliados dicti sunt, qui in negotiis ualidiores sunt: nam et ipse hoc dicit "maius opus moueo". - "Como também dissemos no início, esta obra foi dividida em duas partes: com efeito, disseram-se os seis primeiros [cantos] à maneira da Odisseia, decerto sendo eles de maior relevo pela variedade das personagens e das falas; mas aqueles seis da sequência se disseram à maneira da Ilíada, sendo eles mais consistentes quanto aos trabalhos. Ele mesmo, com efeito, declara: 'obra maior eu ponho em marcha"' (trad. nossa).
} 
insignem pietate uirum, tot adire labores

impulerit. Tantaene animis caelestibus irae? ${ }^{7}$

Ora, tais versos, com que Virgílio abre a Eneida, preenchem funções "inaugurais", a que acima aludimos, pelo menos de mais três maneiras. ${ }^{8}$ Conforme por vezes destacado pelos críticos (Vasconcellos, 2001, p. 115 et seq.), já no primeiro verso o poeta "sumariza" os conteúdos da obra que se inicia, como se arma aludisse à segunda parte da épica (cantos VII a XII) e virum à anterior (cantos I a VI), em anunciação por quiasmo da Ilíada e da Odisseia internas a este poema. De fato, os seis livros iniciais da Eneida focalizam passagens da aventura de Eneias, e dos troianos fugitivos com ele da destruição de Troia pelos gregos, que antecedem o começo dos combates contra Turno na Itália: é a parte "odisseica", ou da viagem à Península (Vasconcellos, 2001, p. 117). Os seis derradeiros, contudo, tomam para objeto narrativo as lutas sangrentas dos troianos e de seus aliados locais contra os rútulos e demais itálicos de Turno, sempre se tendo como meta a aliança com o rei Latino, o casamento com Lavínia, sua filha, e, consequentemente, a plena supremacia política no Lácio; dada a evidente ênfase do tema bélico nos livros deste segundo segmento da obra, tem-se, aqui, a Ilíada do poema (Vasconcellos, 2001, p. 117). ${ }^{\text {? }}$

Além disso, os versos que se seguem ao primeiro da Eneida continuam a resumir, à sua maneira, as aventuras do herói, como ao recordarem a ira de Juno, ferrenha inimiga do povo de Troia inclusive por ter sido preterida por Páris no famoso episódio do julgamento de beleza das deusas (v. 4; v. 8-9), ${ }^{10}$ e os sofrimentos de Eneias "na terra e no mar" (v. 3), decerto atinentes à perda de tantos companheiros em guerra, ${ }^{11}$ à morte dos diletos Anquises

\footnotetext{
${ }^{7}$ Virgílio, Eneida I, 1-11: “As armas e o varão celebro que primeiro, das praias de Troia,/ em fuga por seu destino, veio à Itália e às lavínias/ praias, muito atormentado tanto na terra quanto no mar/ pela força dos deuses, devido à renitente ira de Juno cruel,/ e que também muito suportou na guerra, até fundar uma cidade/ e trazer os deuses ao Lácio, origem do povo latino,/ os pais albanos e os muros da alta Roma./ Musa, lembra-me as causas, pela ofensa a qual vontade/ ou sofrendo o que a rainha dos deuses obrigou/ um homem notável pela piedade a por tantas vicissitudes passar,/ tantos trabalhos enfrentar. Tamanhas as iras nos peitos celestes?" (trad. nossa, a partir de texto latino contido na edição Rizzoli da obra - vejam-se "Referências" ao final).

${ }^{8}$ Para o elementar "comentário" metapoético de Virgílio neste trecho da Eneida, veja-se supra nota 2.

${ }^{9}$ Veja-se supra nota 6.

${ }^{10}$ Veja-se explicação de Pierre Grimal (1963, p. 347): “Lorsque les dieux étaient assemblés pour les noces de Thétis et de Pélée, Eris (la Discorde) lança une pomme d'or au milieu d'eux, disant qu'elle devait être accordée à la 'plus belle' des trois déesses: Athéna, Héra et Aphrodite. Une contestation s'éleva; personne ne voulut se charger de décider entre les trois divinités, et Zéus chargea Hermès de conduire Héra, Athéna et Aphrodite sur l'Ida, où Pâris jugerait le débat. Lorsqu'il vit approcher les divinités, Pâris eut peur et voulut s'enfouir. Mais Hermès le persuada qu'il n'avait rien à craindre, et lui soumit le cas, lui ordonnant de jouer le rôle d'arbitre, au nom de la volonté de Zeus. (...) Pâris décida qu'Aphrodite était la plus belle".

${ }^{11}$ Como Niso e Euríalo, de um famoso episódio do livro IX da épica virgiliana (v. 433 et seq.).
} 
e Creúsa em diferentes pontos de sua trajetória, ${ }^{12}$ à necessidade de abandonar Dido e o amor em fins do livro IV, ${ }^{13}$ para prosseguir em seu duro destino de fundador das bases de Roma...

Ainda, a Musa é invocada em v. 8 como ente facilitador das lembranças que o narrador necessitará ter, a fim de bem contar todos os detalhes da intrincada história que começa; tocamos, aqui, em um elemento poético dos mais tradicionais na Literatura Ocidental, desde os tempos homéricos. ${ }^{14}$ Finalmente, de v. 5 a v. 7 , com a menção à fundação de uma cidade por Eneias, à vinda dos deuses (troianos) ao Lácio e às origens do "povo latino", dos "pais albanos" e dos "muros da alta Roma", realiza-se notório enaltecimento da importância da narrativa em curso, pois que ela trata da própria busca das mais remotas raízes da pátria. Tal efeito de atribuição de importância a essa história (e a seu protagonista), também, parece amplificado em v. 9 e v. 10, operando-se ali pelo reforço da grandeza dos feitos do herói quando se diz que passou por "tantas vicissitudes", enfrentou "tantos trabalhos" e destacouse pela pietas, valor dos mais caros ao ideário romano tradicional. ${ }^{15}$

\section{Características do prólogo de Geórgicas III}

Nesta porção da terceira das partes da obra sob nosso presente foco de análise, Virgílio buscou harmonizá-la com os traços significativos em jogo na própria feitura do livro III em geral. Referimo-nos, com isso, à sabida atribuição, a este livro do poema, do conteúdo técnico da pecuária, seja ela vinculada aos rebanhos de grandes (bois e cavalos) ou pequenos animais (ovinos e caprinos). Ora, como os assuntos tratados a partir de III, 49 mantêm elos com o universo da criação animal, não da agricultura (livro I), da arboricultura (livro II) e da apicultura (livro IV), não faria sentido, por exemplo, que o poeta se dispusesse, ao começar a parte do poema de que aqui nos ocupamos, a cantar aerii mellis caelestia dona ("os dons celestes do mel aéreo" - v. 1), como o faz na derradeira subdivisão da obra.

Em vez disso, nos nove primeiros versos do terceiro prólogo do poema, Virgílio realiza o "recorte", dentre os temas míticos associáveis, ou não, à pecuária, apenas daqueles que ao menos tangenciam tematicamente tal assunto. Isso justifica por que Eurystea durum

\footnotetext{
${ }^{12}$ Anquises é o pai de Eneias, morto na Sicília, cujos jogos fúnebres se celebram no livro V da Eneida; Creúsa foi sua esposa nos tempos de Troia, e lhe aparece já em forma espectral durante a fuga daquela cidade em chamas (II, 776 et seq.).

${ }^{13}$ Veja-se Eneida IV, 393 et seq.

${ }^{14}$ Veja-se supra nota 2.

${ }^{15}$ Pius é um epíteto recorrente para qualificar Eneias na épica virgiliana. Sobre os significados do termo, vejam-se explicações de Pereira (2009, p. 338): "A Pietas define-se habitualmente como um sentimento de obrigação para com aqueles a quem o homem está ligado por natureza (pais, filhos, parentes). Quer dizer, por conseguinte, que liga entre si os membros da comunidade familiar, unida sob a égide da patria potestas, e projetada no pretérito pelo culto dos antepassados. Está, pois, firmada nos sentimentos religiosos dos Romanos (tinha um templo na Urbe desde 181 a.C.), os quais se sentiam protegidos pelos deuses Manes, Lares e Penates, e que pensavam que o dono da casa tinha o seu genius tutelar e a esposa era protegida por Juno”.
} 
("duro Euristeu" - v. 4), Busiridis aras ("altares de Busíris" - v. 5), Hylas puer ("menino Hylas" - v. 6), Latonia Delos ("Delos de Latona" - v. 6), Hypodame ("Hipodâmia" - v. 7) e umeroque Pelops insignis eburno ("Pélope notável pelo ombro de marfim" - v. 7) são rejeitados para o foco de sua atual poesia, enquanto Pales ("Pales" - v. 1), pastor ab Amphryso ("pastor do Anfriso" v. 2) e siluae amnesque Lycaei ("matas e rios do Liceu" - v. 2) se aceitam como temas poéticos.

Assim, explicamos que, pela ordem de nossa citação, Euristeu fora o lendário monarca encarregado de atribuir a Hércules os famosos "Doze Trabalhos" (Grimal, 1963, p. 154), enquanto Busíris, também ligado ao círculo mítico hercúleo, corresponde a um rei egípcio notório pela crueldade, pois torturou e executou, até ser morto pelo herói, todos os hóspedes que recebia mal-intencionado (Grimal, 1963, p. 68-69); Hilas, por sua vez, foi o belo rapaz do qual se enamorou Hércules, que o perdeu para as ninfas quando, em certa parada da viagem dos Argonautas, elas o raptaram, também seduzidas por seus encantos (Grimal, 1963, p. 216); ;6 "Delos de Latona" é o cenário onde a deusa mencionada deu à luz Apolo (Grimal, 1963, p. 259-260); enfim, Hipodâmia e Pélope, esse último com a peculiar característica anatômica dita, correspondem a certa esposa e esposo na mitologia grega, tendo ele sido trazido de volta à vida pelos deuses depois que seu pai o esquartejou, cozeu e serviu em um banquete sacrílego. ${ }^{17}$

Tais personagens e lendas, decerto aventurescas e de interesse para outros poetas e/ ou outras ocasiões compositivas - como se dá em canto VIII, 190-279 da Eneida, quando a personagem mítica de Hércules ganha destaque e ressonâncias políticas coevas $-{ }^{18}$ não se

\footnotetext{
${ }^{16}$ No poema I, XX (v. 37-38), Sexto Propércio menciona a personagem de Hilas, em inserção no evento de seu rapto pelas ninfas de uma fonte aonde fora beber.

17 Veja-se explicação de Commelin (1983, p. 239): “Ovídio conta sobre Pélops a seguinte fábula: 'Tendo ido os deuses alojar-se em casa de Tântalo, esse príncipe, para pôr à prova a sua divindade, fez-lhes servir o corpo de seu filho, misturado com outras carnes. Ceres, um pouco mais gulosa que os outros, já tinha comido uma espádua, quando Júpiter descobriu o crime, restituiu a vida a Pélops, deu-lhe um ombro de marfim para substituir o que Ceres comera, e precipitou seu pai no fundo do Tártaro"'. A lenda mencionada por Commelin, através de Ovídio, encontra-se resumida em Metamorfoses VI, 403-411.

${ }^{18}$ O agora clássico estudo de Philip Hardie (2001 [1986], p. 110 et seq.) demonstrou que Virgílio, no esboço da trama da Eneida, parece ter privilegiado um modelo interpretativo do Império romano segundo o qual esse organismo político, em alguma medida, "espelha” a Ordem cósmica. Assim, do mesmo modo que mitos como a Gigantomaquia, conforme tematizada na Teogonia hesiódica, ilustram e podem dar contornos alegóricos ao enfrentamento entre as forças da Ordem/Olimpo e aquelas do Caos/monstruosidade pelo comando do Universo, outras disputas internas a esse poema épico latino (naturais, míticas ou históricas) surgem ali como variações de um único tema básico, ou seja, a necessidade da repressão aos insurgentes contra todos os poderes "legitimamente" estabelecidos. Nesse sentido, os ventos em turbilhão na cena da tempestade marítima em Eneida I, Marco Antônio e Cleópatra em enfrentamento a Otaviano Augusto, no canto VIII, e o monstro Caco em desafio a Hércules "salvador", também no canto VIII, encarnam em conjunto aqueles que devem ser, "justamente", vencidos e dominados, por causa do potencial destrutivo da harmonia universal que representam. Detalhes que poderiam vincular Caco, especificamente, ao Caos em princípio associável
} 
quadram tão bem ao livro pecuário das Geórgicas quanto as demais vistas, pois Pales era uma deusa (ou deus?) itálica associada à proteção de pastores e rebanhos (Brandão, 1993, p. 238). Além disso, "pastor do Anfriso" identifica-se, no contexto, com uma denominação "agrária" de Apolo, na ocasião em que o deus se pôs a serviço de Admeto, rei de Feras, como boieiro ou guardador de cavalos (Grimal, 1963, p. 42). E as "matas e rios do Liceu" oferecem ao poeta o ensejo de evocar um território natural - o monte arcadiano mencionado - amiúde tido como espaço do nascimento do deus pastoril Pã, onde o veneravam os rústicos (Commelin, 1983, p. 132), além de ser uma zona recoberta por pastagens.

Posteriormente a semelhante "fechamento mítico" dos assuntos cabíveis, iniciase extensa passagem de teor metapoético, na qual, em essência, o poeta fala em trazer as Musas à "pátria" (a cidade de Mântua) e em ali edificar um "templo de mármore" (templum de marmore - v. 13). Ora, a metáfora da edificação para referir-se, na verdade, à feitura de um poema remonta ao poeta grego Píndaro, que dela já se servira ao menos em duas ocasiões compositivas (Ol. 6.1-4: a glorious hall on golden columns.../ Pyth. 6.7-14: a storm-proof treasurebouse of song..... ${ }^{19}$

Tradicionalmente, tem-se interpretado o fazer do "templo" em questão como algo alusivo à futura escrita da Eneida por Virgílio, ${ }^{20}$ pois esse "espaço" é descrito pelo autor com muitas reminiscências bélicas, como os britânicos - tradicionais inimigos externos de Roma - tecidos nas cortinas do teatro (intexti... Britanni - v. 25), as portas decoradas com as "armas de Quirino/do romano vencedor" (uictorisque arma Quirini - v. 27), o "Nifates derrotado" (pulsumque Niphaten - v. 30), o "parto confiante na fuga e nas setas viradas" (fidentemque fuga Partbum uersisque sagittis - v. 31) e os "povos sobre os quais duas vezes se triunfou, de um e outro litoral" (bisque triumphatas utroque ab litore gentis - v. 33); ainda, de forma decisiva para que se sustente a mesma interpretação, Otaviano Augusto (Caesar - v. 16) fora mencionado pelo poeta como alguém postado no meio do edifício, como se assim aludisse até à divindade do príncipe...

aos gigantes dizem respeito a esse monstro, vivendo barbaramente em uma gruta do Lácio, violentando os passantes/nativos do lugar e roubando seus rebanhos, ter tido tamanho desmesurado e, como Tifeu, criatura descomunal sepultada sob o Etna por Júpiter, devido à sua participação malograda na Gigantomaquia, respirar fogo (v. 304). Por outro lado, bem ao meio do escudo de Eneias se divisa Otaviano vencedor contra os "rebeldes" Marco Antônio e a famosa rainha-consorte do Egito, de modo tal que o príncipe se ponha sob a proteção de Apolo e dos demais deuses olímpicos, enquanto seus inimigos lutam sob os auspícios dos "monstruosos" (monstra, v. 698) - porque zooantropomórficos e estrangeiros - deuses egípcios...

${ }^{19}$ Veja-se comentário de Mynors a Geórgicas III, 13 (Virgil, 2003, p. 181).

${ }^{20}$ Veja-se comentário de Thomas ao prólogo inicial de Geórgicas III (Virgil, ed. by Thomas, 1994b, p. 36): "The temple clearly represents an epic, and though the details of the description are contemporary and political (22-3, 46-8; pugnas/ Caesaris), the lines look to the Aeneid, where the implicit presence of Augustus is constant; and V. could hardly be expected to provide a plot summary of a poem whose details must still have been shadowy in his own mind". 
Como sabemos, o usual tema de preenchimento da poesia épica heroica diz sobretudo respeito, desde Homero, ao destaque dos feitos sobre-humanos dos heróis em campo de batalha. ${ }^{21}$ Então, na Ilíada se focalizara um episódio da Guerra de Troia, ou os desdobramentos da chamada "Ira de Aquiles", quando esse se retirou dos combates em protesto por Agamêmnon ter-lhe tomado Briseida, a qual coubera a si em justo butim de campanha. ${ }^{22}$ Desse modo, apenas com a morte de Pátroclo nas mãos de Heitor ele retorna aos combates de maneira desastrosa para os troianos, a fim de vingar o companheiro dileto. ${ }^{23} \mathrm{Na}$ Eneida, por sua vez, ao lado do assunto cronologicamente remoto do estabelecimento das bases de Roma através da vitória militar contra Turno e a consequente fusão dos sangues troiano e itálico, ${ }^{24}$ há evidentes aspectos celebrativos da nascente Casa imperial, a exemplo da figuração de Iulo, o filho de Eneias e mítico ascendente de todo o clã dos Júlios, não só como neto divino de Vênus (Brandão, 1993, p. 37), mas ainda como um dos primeiros fundadores do poderio daquela família na Península, pois, entende-se, depois lhe caberia pelo mito chefiar a cidade de Alba-Longa, donde “sairiam” os próprios Rômulo e Remo (Brandão, 1993, p. 38-39 em citação de Eneida I, 267-288). E não há que esquecer, nesse sentido, de um tocante episódio do livro VI, o encontro, durante a catábase de Eneias, da alma do futuro Marcelo, um sobrinho de Augusto morto precocemente: ${ }^{25}$ essa última homenagem à Casa imperial romana, interessa dizer, também se localiza, distribucionalmente, em contexto central da Eneida.

Depois de apresentar mais alguns elementos físicos do templo, em v. 34-38, os quais, por um lado, prosseguem aludindo às origens troianas de Roma, através da exposição das estátuas dos “descendentes de Assáraco" (Assaraci proles - v. 35), ${ }^{26}$ e, por outro, destinam-se

${ }^{21}$ Já observara sobre a épica Horácio, na Arte poética: "Homero mostrou qual o ritmo apropriado à narração dos feitos dos reis e capitães nas guerras funestas" (v. 73-74 - trad. Jaime Bruna).

${ }^{22}$ Para a discussão do episódio da desonra de Aquiles, veja-se Vivante (1985, p. 81): “The king’s power is not only opposed, it is questioned, denied. He is driven to the brink. He must reassert his authority at all costs, and so he seizes Achille's Briseis. He does so, as he tells Achilles (Il. 1.185ff.): ' $\ldots$ that you may know how much stronger I am than you are/ and others also may shrink from speaking up as my equals/ and matching themselves in my sight"'.

${ }^{23}$ Isso se dá no canto XIX da Ilíada.

${ }^{24}$ Veja-se explicação de Grimal (1994, p. 287): “Avec le chant VI se termine l'Odyssée virgilienne et commence une Iliade: la série des combats qui vont finalement donner la victoire à Énée. Celui-ci n'intervient pas en conquérant brutal. Son premier geste, lorsqu'il arrive en Latium, est de se présenter, pacifiquement, au vieux roi Latinus, qui règne sur le pays, au sud de l'embouchure du Tibre. Un accord est conclu mais, cette fois encore, Junon se met à la traverse et provoque la guerre. (...) Cette ville, qu'Énée fondera une seconde fois après son mariage avec Lavinia, la fille du roi, sera la Lavinium historique". ${ }^{25}$ Em nota a v. 883 de Eneida VI, Riccardo Scarcia explica: "Marco Claudio Marcello, nato nel 43 a.C., da Gaio e Ottavia, sorella di Augusto adottato nel 25 e dato come marito alla figlia Giulia, era probabilmente destinato a succedergli, ma morì prematuramente nel 23 a.C." Veja-se Virgilio, tradução de Riccardo Scarcia, 2002, p. 680.

${ }^{26}$ Como explica Mynors (Virgil, ed. by Mynors, 2003, p. 185), Assáraco era o avô de Anquises, pai de Eneias; assim, um dos fundadores indiretos do poderio romano, através da geração de ascendentes de Eneias. 
apotropaicamente a afastar os danos da invidia ("mau-olhado" - v. 37-39), Virgílio direciona-se do futuro para o presente, ou seja, passa a tratar de aspectos em claro nexo com a feitura da própria obra de que então se ocupa. Tais pontos, de todo alusivos à "ambientação" pecuária de Geórgicas III, correspondem às "matas e clareiras das Dríades" (Dryadum siluas saltusque - v. 40), ao monte Citero (Cithaeron - v. 43), aos "cães taigetos" (Tangetique canes - v. 44) e a "Epidauro domadora de cavalos" (domitrixque Epidaurus equorum - v. 44). Ainda sobre as sucessivas partes e conteúdos deste terceiro prólogo das Geórgicas, vale lembrar que Virgílio o finaliza com nova menção à vindoura empreitada da escrita de um poema épico:

Mox tamen ardentis accingar dicere pugnas

Caesaris et nomen fama tot ferre per annos,

Tithoni prima quot abest ab origine Caesar. ${ }^{27}$

É proveitoso, neste ponto de nossa exposição, examinarmos na passagem virgiliana de nosso interesse a presença das funções que acima dissemos típicas dos prólogos poéticos na Antiguidade, exemplificando com o livro I da Eneida. Elas correspondem, a título de breve recordação, à sumarização dos assuntos de uma obra (ou parcela de obra), à metapoesia, à menção patronal, à invocação divina e a pôr em evidência que os assuntos cuja abordagem se inicia apresentam peso e uma importância justificadora de seu tratamento extenso. Pelo que temos dito ao longo desta segunda subdivisão de nossas análises, a primeira função citada, de "resumo" dos tópicos técnicos da criação, até certo ponto se identifica distribucionalmente com o trecho dos versos 40-45, nos quais Virgílio situa seu fazer artístico coevo como algo em nexo com a ambientação pecuária. Na verdade, as "matas e clareiras das Dríades" (v. 40) evocam divindades atinentes à dimensão rústica ${ }^{28}$ e espaços de todo associáveis ao apascentamento de rebanhos; o "Citero e os cães taigetos" (v. 43-44) aludem a uma montanha e a seres em respectiva participação no universo do pastoreio (Virgil, ed. by Mynors, 2003, p. 187) ou das caçadas $^{29}$ - para as quais é útil servir-se também de cavalos, um dos tipos animais em seguida recobertos pela preceituação do magister didático em Geórgicas III -; "Epidauro domadora de cavalos", 30 é óbvio, presta-se a tematizar de passagem o mesmo tópico do trato de equinos.

${ }^{27}$ Virgílio, Geórgicas III, 46-48: "Logo, contudo, eu me disporei a contar as ardentes batalhas/ de César e a divulgar seu nome com a fama por tantos anos/ quanto dista César da primordial origem de Titono" (trad. nossa).

${ }^{28}$ As Dríades correspondiam a ninfas dos bosques ou, especificamente, dos carvalhos, como nos explica Brandão (2009, p. 225).

${ }^{29}$ Veja-se comentário de Mynors a Geórgicas III, 44 (Virgil, ed. by Mynors, 2003, p. 187): “T. is the great ridge of mountains that bounds the plain of Sparta on the west and runs down to form the central prong of the Peloponnese. There was good sport there from wild goats, as well as boar, deer, and bear (Pausanias 3.204), and hence it was a favorite haunt of Diana the huntress (Hom. Od. 5.103, Callim. Dian. 188). Here, as is Prop. 3.14.15, it identifies the Spartan hounds; (...)".

${ }^{30}$ Veja-se comentário de Mynors a Geórgicas III, 44 (Virgil, ed. by Mynors, 2003, p. 188): "Strabo 8.8.1 groups together as excellent the breeds of Arcadia, the Argolid and Epidaurus (which Serv. confuses with Epirus, cf. 121). Domitrix, which first appears here in extant Latin, represents with equorum Homer's hippódamos". 
Como vemos, uma vez que se abordam tecnicamente, em Geórgicas III, a criação de grandes (equinos e bovinos, até v. 285) e a de pequenos animais (caprinos e ovinos, de v. 286 a v. 473) e os meios alusivos vistos há pouco, empregados pelo poeta para referir-se a isso tudo, parecem privilegiar, além dos cães, ora os rebanhos miúdos - os quais, em princípio, movimentam-se e pastam com mais facilidade em ambientes não tão abertos quanto matas e clareiras, ou íngremes como o Citero -, ora os cavalos (de Epidauro), o tópico dos cuidados dos bois não recebe destacada referência entre v. 40-45, a não ser sutilmente, por um detalhe que diríamos indireto. Ocorre, com efeito, quando da menção ao fato de que, ao se realizarem caçadas, "o barulho ecoa dobrado pelo assentimento dos bosques" (uox adsensu nemorum ingeminata remugit - v. 45), ser esse tipo animal ao menos evocado por Virgílio nos planos etimológico, dada a clara proveniência de remugire ("ecoar", "ressoar") do mais direto mugire, termo indicativo em latim da "voz" dos bovinos, e sonoro, pois é notório que as duas formas verbais aludidas apresentam efeitos e origens onomatopaicas. ${ }^{31}$

Além disso, no idêntico quesito da sumarização dos tópicos pecuários do livro III, convém observar que a própria supracitada recusa, pelo poeta, dos assuntos míticos sem correlação com o universo da criação animal acaba por operar em sentido afim, pois, do mesmo modo que personagens e espaços lendários sem nexo imediato com tal assunto não interessam presentemente a ele para a incorporação à obra, pressupõe-se também não vir a ter lugar o efetivo tratamento de temas técnicos sem elos estritos com os rebanhos e manadas. Neste caso, Virgílio opera por exclusão do que é estranho a seu foco essencial de preceituação didática em Geórgicas III, em primeira triagem de todos os assuntos em princípio existentes, não propriamente pela citação desenvolvida dos pontos a serem abordados ao "ensinar" os assuntos pecuários ao "aluno". Contudo, através de tal procedimento - obviamente acrescido de aceitar "Pales", o "pastor do Anfriso" e as "matas e rios do Liceu" -, ele ao menos sinaliza ao leitor, por elementos dotados de razoável clareza, direcionar tematicamente o livro III para os assuntos pecuários, não para aqueles agrários (como no livro I), de arboricultura (como no II) e de apicultura (como no IV); com isso, por conseguinte, o poeta já sugere alguma menção aos prováveis assuntos de que há de ocupar-se na sequência.

Também nos parece útil lembrar aqui a existência, internamente ao mesmo livro III das Geórgicas, de uma passagem a que a crítica por vezes tem chamado de "segundo prólogo" dessa parte do texto: ${ }^{32}$ tal trecho corresponde aos versos 284-294, que antecedem

\footnotetext{
${ }^{31}$ Como observa Faria (1970, p. 95), "os gramáticos latinos são todos muito explícitos nas descrições que nos dão do $m$, insistindo particularmente em sua qualidade de nasal e bilabial: ' $m$ ' impressis inuicem labiis mugitum quendam intra oris speculum atractis naribus dabit (M. Vitorino, Keil, 6, 34, 12) - 'o $m$ produzirá como que um mugido dentro da cavidade bucal, apertados os lábios, um no outro, e contraídas as narinas"”.

32 Veja-se comentário de Thomas a Geórgicas III, 284-294 (Virgil, ed. by Thomas, 1994b, p. 95): “The proem to the second book (treating smaller animals) balances that at 1-48; see 292-3, 294nn. The passage also looks to the opening of Book 4 (286, 289-90nn.). This proem helps to underscore the bipartite nature of the book, and ultimately to emphasize the two great crescendos which in each half follow the technical or didactic parts - the twin devastations brought by amor and by the plague".
} 
a efetiva entrada na abordagem técnica do trato de ovinos e caprinos. Ele contém, a título de resumida apresentação, depois de uma "nota" rápida sobre a necessidade de correr contra o tempo, com vistas à plena completude da tarefa a que o poeta se propusera quando do início da planificação das Geórgicas, dizeres relativos à dificuldade de "vencer com palavras" (uerbis... uincere - v. 289) um tema tão humilde, em claras proposições de teor metapoético. Em seguida, já mais "confortado" com as perspectivas de glória caso capaz de levar a cabo tarefa tão árdua, Virgílio metaforiza a escrita desta parcela das Geórgicas como uma subida aos "cimos desertos do Parnaso" (Parnasi deserta per ardua - v. 291) 33 e a rolagem de um carro em direção a Castália, fonte das imediações de Delfos em conhecida associação com a inspiração vática (qua nulla priorum/ Castaliam molli deuertitur orbita cliuo - v. 292-293). ${ }^{34}$ Enfim, em v. 294, surge nova menção à deusa pastoril "Pales", que deve auxiliá-lo a "ressoar em alta voz" (magno... ore sonandum).

Esse "segundo prólogo", com efeito, continua, de maneira mais precisa e direcionada, as funções do primeiro, por exemplo sumarizando haver de se constituir a segunda parcela da abordagem técnica do livro III em específica focalização do trato dos pequenos animais (lanigeros agitare greges hirtasque capellas - v. 287). Também ressurge, aqui, a metapoesia, ${ }^{35}$ a qual já divisáramos no grande prólogo de abertura do mesmo livro pela elaborada imagem da construção futura de um templo/poema épico, além de pelos dizeres relativos a que, nas próprias circunstâncias de escrita das Geórgicas, mais valia dedicar-se a assuntos humildes, em conformidade com os haud mollia iussa - "ordens não fáceis", v. 41 - de Mecenas, o patrono da obra inteira (livro I, v. 2).

Além disso, frisamos de novo que a menção, ou invocação, ou direta interpelação aos deuses, a qual se nota no "segundo prólogo" a propósito da presença do nome de "Pales", como vimos, é um elemento de grande importância e frequente surgimento em partes "inaugurais" de várias obras literárias antigas, como atestam os exemplos supracitados de Homero $^{36}$ e do Virgílio da Eneida. Ora, embora isso não se desse tão tipicamente no prólogo inicial do livro III das Geórgicas quando o poeta refere as Musas (v. 11) que trará a Mântua dos "Píncaros aônios" (Aonio... uertice), pois ali apenas se fala delas em terceira pessoa, as menções "divinas" a "Pales" (v. 1), a Apolo/"pastor do Anfriso" (v. 2) e às "matas e rios do Liceu” (v. 2, em possível associação com o deus rústico Pã, bem o vimos), cumprem à sua maneira, no contexto local, a função estereotipada do estabelecimento de contato com os deuses nos começos.

Com efeito, mesmo que também evocativas dos temas pecuários do livro em que se encontram, ou deles delimitadoras de maneira elementar, como antes intentamos dizer, as

\footnotetext{
${ }^{33}$ Trata-se de uma montanha mais de uma vez associada, no mundo antigo, à inspiração poética, por exemplo, em Bucólicas VI, 29: Nec tantum Phoebo gaudet Parnasia rupes. - "Nem tanto com Febo se alegra o monte Parnaso" (Virgil, ed. by Thomas, 1994b, p. 97).

34 "Por onde nenhum carro/ dos antigos vai dar em Castália por suave vertente" (trad. nossa); veja-se comentário de Mynors a Geórgicas III, 292-293 (Virgil, ed. by Mynors, 2003, p. 226).

${ }^{35}$ Veja-se supra nota 2.

${ }^{36}$ Veja-se supra nota 2.
} 
diretas interpelações a esses três elementos revestem-se de teores afins à clássica invocação às Musas, na medida em que estão relacionadas ao elemento celebrativo do canto (canemosv. 1), ${ }^{37}$ que Apolo, com alguma frequência, também foi considerado um deus inspirador dos poetas $^{38}$ e que, no "segundo prólogo", "Pales" ressurge em clara função de auxílio ao canto geórgico, naquele ponto da obra dificultado pela grande humildade do subtópico em pauta.

Em seguida, como o elemento patronal é postergado no prólogo inicial de Geórgicas III, ${ }^{39}$ além das funções de sumário, metalinguística e de conexão com os entes supremos, esse começo de livro destaca primeiro a importância dos assuntos da parte da obra em que se encontra por explicitar, de início, que não se trata de temas que já "detiveram mentes vazias com um poema" (quae uacuas tenuissent carmine mentes - v. 3), a exemplo, pelo contrário, das lendas rejeitadas de Hilas, de Pélope e Hipodâmia etc. Com isso, o poeta diferencia o maior "peso" dos conteúdos de que, doravante, há de ocupar-se da frivolidade, ou significativo desgaste, daqueles que não aceita, dizendo ainda crer-se capaz de "erguer-se do chão" (tollere bumo - v. 9) e "voejar vencedor pelas bocas dos homens" (uictorque uirum uolitare per ora - v. 9), em evidente alusão às esperanças de sucesso (e fama) da ousada empreitada poética a que então se dedica.

Por outro lado, outros elementos prologais contribuem para pôr em destaque que aquilo a que se votará o poeta também no livro III, com a abordagem, até humilde, da criação de animais de rebanho, não corresponde a meras banalidades: mencionamos as afirmações relativas aos haud mollia iussa de Mecenas (v. 41), bem como a ideia virgiliana de que, sem a intervenção desta personagem histórica (e amigo), "a nada de alto o espírito se lança" (nil altum mens incohat - v. 42). Nesses casos, se o fazer compositivo de Virgílio na presente subdivisão da obra, o qual inclui assimilar e trabalhar poeticamente o tema da pecuária, de nada valesse em sua maior "humildade" - pois sequer deparamos aqui um contínuo empenho de composição épica! -, os esforços do poeta em tais circunstâncias também não lhe serviriam, através do embate pessoal por bem sair-se de uma dura tarefa a si confiada por Mecenas, ao

\footnotetext{
${ }^{37}$ No exemplo supracitado de Odisseia I, 1, bem como em Ilíada I, 1, havia respectivas invocações a uma "Musa" e a uma "deusa" / theá (Ilíada I, 1-3: "Canta-me, ó deusa, do Peleio Aquiles/ A ira tenaz, que lutosa aos Gregos/ Verdes no Orco lançou mil fortes almas” - trad. Odorico Mendes), para que auxiliassem o poeta no canto. Em Eneida I, 8, porém, a Musa aparece como agente de lembrança, não de cantar, o que, apesar de "desviado" dos usos homéricos no mesmo aspecto, não deixa de justificar-se, pois as Musas eram, na mitologia grega, filhas de Mnemosyne, deusa da memória gerada por Urano e Gaia, e que as gerou depois de unir-se a Zeus (Grimal, 1963, p. 300).

${ }^{38}$ Ovídio se lembra desta tradição no início do livro I (v. 25-30) da Ars amatoria, ainda que, circunstancialmente, para negá-la: Non ego, Phoebe, datas a te mibi mentiar artes, / nec nos aeriae noce monemur auis, / nec mihi sunt uisae Clio Cliusque sorores/ seruanti pecudes uallibus, Ascra, tuis:/ usus opus mouet hoc: nati parete perito;/ uera canam: coeptis, mater Amoris, ades! - "Eu, ó Febo, não fingirei que me dotaste com tal arte;/ nem me inspirou o pio da aérea ave,/ nem avistei Clio ou suas irmãs,/ guardando eu, ó Ascra, o gado nos teus vales./ A experiência move esta obra: obedecei ao vate perito./ Verdades cantarei; ó mãe do Amor, favorece-me o intento!" (trad. nossa).

${ }^{39} \mathrm{Na}$ verdade, para v. 41 do mesmo livro.
} 
fortalecimento como artista capaz de abordar temas tão áridos. Além disso, envolver-se com a escrita das Geórgicas equivale a algo "alto", como atesta o v. 42, de maneira inegavelmente inclusiva de todos os elementos necessários a elaborar sua complexa estrutura.

Então, embora se tenha de concordar com que talvez resulte tal aspecto do prólogo de Geórgicas III - vale dizer, a função nobilitadora dos assuntos tratados - por vezes sobreposto, ou relativamente eclipsado, pela valorização do próprio fazer poético, fatores como a ênfase pelo magister didático de sua ocupação com um tema não frívolo (ou vulgarizado em demasia), bem como capaz, com outros elementos compositivos, de fazê-lo "ascender", decerto contribuem para conceder-lhe algum destaque.

\section{O PRÓlogo de Geórgicas i e os PRÓlogos dos DEMAIS liVRos do POEMA}

Neste subtópico analítico, deve-se inicialmente registrar que os dois prólogos dos livros ímpares das Geórgicas são os mais elaborados da obra inteira, o que já se depreende de sua extensão, com respectivos 42 (I) e 48 (III) versos cada; em contrapartida, esse mesmo quesito numérico ajuda a divisar nos prólogos do livro II e do livro IV apenas 8 e 7 versos.

Não é preciso, porém, restringir a constatação dessa maior complexidade dos prólogos ímpares ao critério quantitativo dos versos, pois sua organização mesma, em várias partes interligadas, contribui para sustentar-nos a afirmação: em Geórgicas I, assim, tem-se um exordium, no mínimo, constituído por 3 partes. São elas a proposição inicial de todos os assuntos do poema (v. 1 a 5, com a disposição de um assunto por verso), a prece aos doze deuses rústicos, o que, à sua maneira, Virgílio retoma do livro I do De re rustica de Varrão, ${ }^{40}$ e a algo "incomum" prece a Otaviano Augusto (Caesar),${ }^{41}$ no contexto tornado uma espécie de Nume tutelar dos camponeses itálicos, ou persona de mais vastos atributos. Bastando-nos o que já dissemos sobre as sucessivas partes do prólogo do livro III, apenas lembramos, a esse respeito, que ele também nos parecia poder dividir-se em três partes principais, correspondentes aos v. 1-9 (aceitação ou negação "sumarizadoras” de temas poéticos),

\footnotetext{
${ }^{40}$ Veja-se comentário de Wilkinson (1997, p. 65): "The De re rustica has pretensions to being literature. It is a dialogue in the Ciceronian manner. And in several passages of a literary kind it would seem to have influenced Virgil. The invocation to the twelve gods at I.I.5-6 no doubt suggested Virgil's invocation to his different twelve gods in his exordium, which was probably written last as exordia generally were".

${ }^{41}$ Veja-se Wilkinson (1997, p. 162-3): “The idea of divine honours for rulers had long been familiar in Asiatic, Greek and Punic lands. There had recently been a wave of claim and expectations. Sextus Pompeius had given out that he was son of Neptune. Antony had been hailed as Dionysus at Athens, Ephesus and Alexandria. These ideas had once been regarded at Rome as foreign, but there were native customs that could ease their acceptance. The cult of the manes and the sacrifices of parentatio could lead to the worship of a dead ruler, as could philosophic ideas of deification for services to men such as we find in Cicero's Somnium Scipionis. Worship of a living man was more difficult, but helped by the notion of worshipping the genius of the paterfamilias and by Stoic ideas of the divine nature of the human soul".
} 
v. 10-39 (metáfora complexa da futura feitura de um poema épico como construção de um templo marmóreo às margens do rio Míncio, em Mântua) e v. 40-48 (retorno, da maior sublimidade épica, para o plano didático do presente texto, com indicação de aspectos "pecuários" como o "Citero" e "Epidauro domadora de cavalos").

Ainda, não é apenas pelo fato de iniciarem longamente livros ímpares das Geórgicas e assim se estruturarem em tripartição que tais prólogos se parecem: segundo demonstrado por análises formais e de conteúdo dos filólogos, Virgílio nitidamente parece ter organizado o poema em duas metades sucessivas e complementares, porém, até certo ponto, "autônomas". Então, os livros I e II contêm, respectivamente, o total de 514 e 542 versos; os livros III e IV, por sua vez, contêm ambos 566 versos. Além disso, os dois livros do início focalizam-se na abordagem de tópicos em elo com a vida vegetal - campos de cultivo e arboricultura -, enquanto os dois últimos se concentram na preceituação técnica a respeito de assuntos em nexo com os animais - pecuária e apicultura. No tocante, propriamente, aos elos internos entre o par de livros III e IV, uma arguta observação de Hardie, ${ }^{42}$ sobre o meio da derradeira divisão da obra retomar certa situação específica, a saber, a morte de todos os animais possuídos por alguém, de fins do livro terceiro, ajuda a divisá-los em nexo mais estreito do que um olhar apenas desatento poderia levar a crer.

Faz-se, aqui, necessário lembrar que, em livro III, os entornos de v. 474 já descrevem o horrendo episódio da "Peste Nórica", no qual todos os rebanhos, seguidos dos animais silvestres e até dos homens renitentes em permanecer naquelas desoladas paragens de alémAlpes, são infectados por um mal terrível e incurável, cujas causas permanecem obscuras no "quadro" virgiliano. ${ }^{43}$ Disso resulta, então, que os animais dos nóricos sejam enfim aniquilados por completo, deixando-os desprovidos de seu bem mais precioso. $\mathrm{Na}$ "metade" do livro IV (v. 317 et seq.), de novo ocorre que divisemos a perda das "posses animais" de alguém, desta vez, porém, tratando-se dos enxames de abelhas de Aristeu, mítico filho de Apolo e da ninfa Cirene. Mas, à total diferença do ocorrido no livro III, tal perda de enxames encontra definitiva solução no próprio livro IV, com o retorno à vida das abelhas a partir de v. 554 .

Tem-se, com efeito, que o extermínio desses animais fora o resultado da vingança dos Manes $^{44}$ de Orfeu e Eurídice, pois Aristeu perseguira a moça nos campos em certo

\footnotetext{
${ }^{42}$ Veja-se Hardie (1998, p. 49).

${ }^{43}$ Veja-se comentário de Gale sobre a indefinição dos sentidos do sacrifício purificador oferecido pelos nóricos em Geórgicas III, 486-497, bem como da "Peste" como um todo (2000, p. 109): "In Georgics I, then, sacrifice is positively recommended; in book 2, it becomes more problematic. In book 3 further doubt is shed on its validity, as I suggested earlier. The plague itself makes even the attempt to placate the gods impossible, as animals die before they can be sacrificed. But the air of uncertainty here is increased still further by the fact that the description of the sacrificial victim's death very strongly recalls Lucretius' account of the sacrifice of Iphigenia".

${ }^{44}$ Veja-se Brandão (1993, p. 213): “Manes (Di), -ium, deuses Manes. O nome, segundo Ernout-Meillet, DIEL, p. 383, é interpretado como plural de manis e significaria 'deuses benevolentes', epíteto com que se designavam, por eufemismo, o espírito dos mortos e, em especial, 'os antepassados divinizados', di parentes. (...) Diga-se, além do mais, que só mesmo por eufemismo é que Manes podem significar
} 
episódio de descontrole passional, daí resultando a inadvertida pisada dela sobre uma serpente peçonhenta, durante a fuga ao estupro, e sua morte em decorrência do veneno (v. 457-459). Assim, o desespero de Orfeu, seu esposo, a vã tentativa dele de recuperá-la à morte em catábase (v. 467 et seq.) e o próprio aniquilamento desse homem nas mãos das Bacantes trácias (v. 520-522) ocasionaram a revolta dos dois lesados contra o involuntário instigador de suas dores e, então, uma "revanche", sob a forma do mal que lhe vitimou as abelhas. A solução encontrada por Aristeu, enfim, que se aconselhara com a mãe e com o deus marinho Proteu, foi realizar, pela primeira vez, o rito expiatório da bugonia, pelo qual bovinos sacrificados aos Manes dos ofendidos vieram a purificá-lo de sua culpa e favorecer que suas abelhas tornassem à vida, reconduzindo-o a uma situação de plena normalidade, incompatível com a desolação dos nóricos em fins do livro III.

A retomada do conflito do livro anterior, por conseguinte, para resolvê-lo em definitivo no livro IV, contribui para ligar fortemente essas duas partes do poema, como se algo antes suspenso viesse, com o estrutural prosseguimento das Geórgicas, a receber seu pleno fecho. Tais "parênteses" narrativos serviram-nos a dar a entender que, se os livros I e II formam um "todo" relativamente autônomo do poema, por suas afinidades formais e de conteúdo (como o número diferente de versos quando comparados os dois entre si e os assuntos distintos da abordagem da vida animal), e os livros III e IV outro "todo", por semelhantes motivos e ainda por se interligarem através da retomada interna do tema da morte, então os prólogos de I e III sempre apresentam a função de abrir metades distintas da obra, cada qual constituída por duas partes imbricadas.

Quanto a algumas diferenças entre os prólogos de I e III, notamos, sobretudo, que no primeiro havia de chofre a menção a Mecenas, provável instigador da obra e homenageado $\operatorname{logo}$ em v. 2, enquanto, no terceiro, esta mesma personagem apenas surgiria em v. 41, evocada a propósito dos hand mollia iussa a que nos referimos. Curiosamente, porém, em espécie de recíproca inversão do momento de evocar "César", o príncipe aguarda, no livro I, até v. 25 para ser nomeado, enquanto, no livro III, é citado já em v. 16. O livro I, ainda, com suas duas extensas invocações divinas - aos doze Numes rústicos e ao próprio "César"/Otaviano Augusto - focaliza-se, tematicamente, no aspecto religioso (ou encomiástico), além de prestarse à introdução geral da obra, enquanto o livro III parece privilegiar, pelo que dissemos, aspectos metapoéticos e a introdução do tema pecuário, a qual ainda se desdobra com maior especialização no "segundo prólogo" da mesma subdivisão do texto.

Quanto, enfim, aos prólogos do livro II e IV, que introduzem os assuntos técnicos da arboricultura e do trato das abelhas, o primeiro deles se diferencia do de Geórgicas III na medida em que se concentra em uma direta interpelação ao deus Baco, a qual se processa

\footnotetext{
'os bons, os benevolentes'. A realidade é bem outra. Na Eneida, para citar apenas uma obra literária, os mortos, uma vez elevados à condição de Manes, também vão engrossar as fileiras dos carrascos de além-túmulo. (...) Não há dúvida de que os mortos, como se os vivos fossem culpados pela morte ou por não se conformarem com ela, vinham, de quando em quando, na sua imensa insatisfação, atormentar seus irmãos, que ainda viam a luz do dia”.
} 
“ininterruptamente" de v. 2 a v. 8; ${ }^{45}$ além disso, como os livros ímpares das Geórgicas foram, muitas vezes, considerados mais "pessimistas" que os pares e o livro I acabara com imagens bastante tétricas, como as dos portentos que se seguiram ao assassinato de Júlio César e as da perda do controle de um carro guiado por cavalos por seu condutor (v. 512-514), em espécie de vívida metáfora do descontrole humano diante das guerras e atribulações políticas coevas ao poeta, o prólogo de Geórgicas II se distingue daquele de III ao significar um "escape de pesadelo", nos termos de Wilkinson (1997, p. 85).

Algo semelhante se dá com o de IV, na verdade identificado, em seus cinco primeiros versos, com uma sumarização dos vários subtópicos de apicultura a receberem nele posterior abordagem e depois, nos dois seguintes, com um pequeno comentário de natureza metapoética, sobre ser tal assunto tenuis ("ligeiro"): ${ }^{46}$ como se viu, o livro III termina com o grave desfecho da "Peste Nórica", ou seja, com o contágio da terrível doença até sobre os seres humanos. Portanto, novo despertar de um "sonho ruim" ocorre quando adentramos o derradeiro prólogo das Geórgicas, algo impensável diante do anterior.

\section{Conclusão}

Os dados acima apresentados permitem observar que o prólogo de Geórgicas III se reveste de múltiplas funções retórico-poéticas, depois retomadas, exceto a quarta, no começo

\footnotetext{
${ }^{45}$ Reforçamos com maior precisão e alcance analítico que, em mostra do harmonizador cuidado construtivo das Geórgicas, os livros pares da obra (II e IV) parecem-nos sempre conter prólogos separados em duas partes; os ímpares (I e III), por sua vez, em três. O prólogo de II, então, comporta uma sumarização muito breve - os três versos iniciais - dos assuntos de arboricultura e, em seguida (v. 4-8), uma "prece", ou invocação a Baco; no prólogo de IV, contudo, depois dos versos iniciais, de endereçamento a Mecenas e sumarização dos tópicos de apicultura a serem tratados logo na sequência (v. 1-5), tecem-se brevíssimos comentários sobre o caráter tenuis ("delicado") de tal parte da obra, por seus assuntos "diminutos", e a necessidade do auxílio de Apolo a esta específica tentativa virgiliana de compor. Ainda, as respectivas partes do primeiro e terceiro prólogo são, a mero título de lembrança, I- a proposição geral dos assuntos da obra (v. 1-5), a prece aos doze deuses rústicos (v. 5-23) e a "prece" a Augusto (v. 24-42); III- "recorte" dos mitos e assuntos convenientes (ou não) a um livro pecuário (v. 1-9), metáfora épica do templo de Mântua (v. 10-39) e o "retorno", com o fecho do prólogo, das alturas heroicas para a poesia didática agrária das Geórgicas.

${ }^{46}$ Veja-se supra nota 45 e comentário de Thomas a Geórgicas IV, 6-7 [Virgil, edited by R. F. Thomas, 1994b, p. 148-149: "6 in tenui labor; at tenuis non gloria: the antithesis is familiar from the second proem of Book 3: angustis bunc addere rebus honorem, 290; on the Callimachean language, and the programmatic sense of the line, see Introduction, pp. 1-3. The line also suggests that the stylistic approach will be correctly Callimachean (tenuis = leptós), while the theme and the glory accruing from it will be of a larger, non-Callimachean nature; or, in other words, ars and ingenium will be both accommodated. V. surely noticed Varro's characterization of the bees at R.R. 3.16 .3 uolucres, quibus plurimum natura ingeni atque artis tribuit. (...) 6-7 auditque nocatus Apollo: cf. A. 3.395 aderitque nocatus Apollo. Apollo Nomius, guardian of shepherds, appeared at 3.2 (3.1-2n.), but here he is the god of poetry, a function inherited from Alexandria by Augustan poets".].
} 
de Eneida I: 1. a sumarização dos assuntos a serem abordados por Virgílio nessa subdivisão da obra, 2. a metalinguagem - que ocorre ali sobretudo sob a metáfora elaborada da feitura do templo às margens do Míncio -, 3. a invocação divina, 4. o estabelecimento de elos com um patrono/Mecenas e 5. algum realce dos tópicos técnicos abordados na mesma parte do poema. Evidentemente, procedendo à junção e combinação desses elementos, o poeta não operou em um vácuo criativo, mas deu curso a práticas compositivas que remontam, na verdade, ao gesto "fundador" de Homero.

No tocante, por sua vez, não à análise "isolada" do mesmo prólogo geórgico, mas sim a seu delineamento no cotejo com os demais do poema no qual se encaixa, divisamos aspectos que ora contribuem para sua distância, ora para sua aproximação diante de outros elementos de um conjunto maior. Assim também se nota, pelo exame do presente subtópico, que o "poema da terra" de Virgílio recebeu cuidada elaboração no plano organizacional dos livros e, ainda, acolheu mecanismos retórico-formais "mapeadores" de certos modos de leitura cabíveis para o texto em pauta.

\section{REFERÊNCIAS}

ARISTÓTELES; HORÁCIO; LONGINO. A poética clássica. Trad. J. Bruna. São Paulo: Cultrix, 2007.

BRANDÃO, Junito de Souza. Dicionário mítico-etimológico. Mitologia e religião romana. Petrópolis: Vozes, 1993.

BRANDÃO, Junito de Souza. Mitologia grega. 18 ed. Petrópolis: Vozes, 2009. v. 1.

CAMÕES, Luís Vaz de. Os Lusíadas. São Paulo: Cultrix, 1991.

CICERO. AdC. Herennium libri IV de ratione dicendi. Translated by H. Caplan. Cambridge, MA: Harvard University Press, 1964.

COMMELIN, Pierre. Mitologia grega e romana. Trad. Thomaz Lopes. Belo Horizonte: Itatiaia, 1983.

DALZELL, Alexander. The Criticism of Didactic Poetry. Essays on Lucretius, Virgil and Ovid. Toronto: University of Toronto Press, 1996.

FARIA, Ernesto. Fonética bistórica do latim. Rio de Janeiro: Livraria Acadêmica, 1970.

FONTES Jr., Joaquim Brasil. O livro dos simulacros. Florianópolis: Clavicórdio, 2000.

GAFFIOT, Félix. Dictionnaire latin-français. Paris: Hachette, 1934.

GALE, Monica Rachel. Virgil on the nature of things. Cambridge: Cambridge University Press, 2000.

GRIMAL, Pierre. Dictionnaire de la mythologie grecque. Paris: Presses Universitaires de France, 1963. 
GRIMAL, Pierre. La littérature latine. Paris: Fayard, 1994.

HARDIE, Philip. Virgil's "Aeneid”. Cosmos and Imperium. Oxford: Oxford University Press, 2001 [1986].

HARDIE, Philip. Virgil. Greece and Rome. New surveys in the classics number 28. Oxford: Oxford University Press, 1998.

HOMERO. Ilíada. Trad. O. Mendes. Rio de Janeiro; São Paulo; Porto Alegre: Clássicos Jackson, 1950.

HOMERO. Odisseia. Trad. Trajano Vieira. São Paulo: Editora 34, 2011.

JANSON, Tore. Latin prose prefaces. Studies in literary conventions. Stockholm; Göteborg; Uppsala: Almquist \& Wiksell, 1964.

MAURUS SERVIUS HONORATUS. In Vergilii carmina Comentarii. Servii Grammatici qui feruntur in Vergilii carmina Commentarii. Recensuerunt Georgius Thilo et Hermannus Hagen. Leipzig: B. G. Teubner, 1881. Disponível em: http://www.perseus.tufts.edu/hopper/ text?doc=Perseus\%3Atext\%3A1999.02.0053. Acesso em: 2 jul. 2019.

OVIDIO. Ars amatoria. Trad. N. Correia e D. Mourão-Ferreira. São Paulo: Ars Poetica, 1993.

OVIDIO. Metamorfosi. Con un saggio di Italo Calvino, trad. Piero Bernardini Marzolla. Torino: Einaudi, 1994.

PEREIRA, Maria Helena da Rocha. Estudos de bistória da cultura clássica. Vol. II - cultura romana. Lisboa: Gulbenkian, 2009.

PERNOT, Laurent. La rhétorique dans l'Antiquité. Paris: Le Livre de Poche, 2000.

PROPERCE. Élégies. Trad. nouvelle avec une introduction et des notes par Maurice Rat. Paris: Librairie Garnier Frères, 1931.

ROBERT, Jean-Noël. La vie à la campagne dans l'Antiquité romaine. Paris: Les Belles Lettres, 1985.

SARAIVA, Francisco Rodrigues dos Santos. Novíssimo dicionário latino-português. Rio de Janeiro; Belo Horizonte: Garnier, 1993.

SHARROCK, Alison. Seduction and repetition in Ovid's "Ars amatoria" 2. Oxford: Clarendon Press, 1994.

TREVIZAM, Matheus. Descrição zoológica e intertextualidade na poesia didática romana: Virgilio e "Cinegéticos". Phaos, v. 18, n. 1, p. 78-96, jan./jun. 2018.

VASCONCELLOS, Paulo Sérgio de. Efeitos intertextuais na "Eneida" de Virgílio. São Paulo: Humanitas/ Fapesp, 2001.

VIRGIL. Georgics. Edited with a commentary by R. A. B. Mynors. Oxford: Oxford University Press, 2003. 
VIRGIL. Georgics. Volume I. Books I-II. Edited by R. F. Thomas. Cambridge: Cambridge University Press, 1994a.

VIRGIL. Georgics. Volume II. Books III-IV. Edited by R. F. Thomas. Cambridge: Cambridge University Press, 1994b.

VIRGILE. Bucoliques. Texte établi et traduit par E. de Saint-Denis. Paris: Les Belles Lettres, 2002.

VIRGILE. Géorgiques. Texte trad. par E. de Saint-Denis, introduction, notes et postface par Jackie Pigeaud. Paris: Les Belles Lettres, 1998.

VIRGILIO. Eneide. Intr. Antonio La Penna, trad. e note di Riccardo Scarcia. Milano: Rizzoli, 2002. v. 1, libri 1-6.

VIVANTE, Paolo. Homer. New Haven: Yale University Press, 1985.

WILKINSON, Lancelot Patrick. The "Georgics" of Virgil. A critical survey. Norman: University of Oklahoma Press, 1997. 